\title{
Capsule Commentary on Baumgartner et al., Aspirin Compared with Anticoagulation to Prevent Venous Thromboembolism after Knee or Hip Arthroplasty: a Large Retrospective Cohort Study
}

\author{
Gregory J. Misky, MD \\ $\mathrm{J}$ Gen Intern Med 34(10):2187 \\ DOI: $10.1007 / \mathrm{s} 11606-019-05170-9$ \\ (c) Society of General Internal Medicine 2019
}

University of Colorado Anschutz Medical Campus, Aurora, CO, USA.

$\mathrm{B}$ aumgartner et al. examined the prophylactic practices of elective primary hip and knee arthroplasties over 2 years, comparing aspirin with other pharmacologic agents in preventing venous thromboembolism (VTE). ${ }^{1}$ As might be expected, based upon the most recent American College of Chest Physician (ACCP) guidelines that includes aspirin (ASA) as an acceptable pharmacologic alternative in VTE prophylaxis, use of aspirin in this patient population has increased over time. ${ }^{2}$ And despite this increase in postoperative joint patients receiving aspirin only (vs. other agents), no increase in clinically significant venous thromboembolism was identified out to 90 days.

The interpretation of the results of this retrospective study may be methodologically limited, as data was obtained through administrative billing data and ICD codes. In addition, caution is also warranted based on confounding variables including patients who received both anticoagulation and ASA were older and had higher cardiovascular comorbidities and higher Caprini scores, while ASA-only patients were generally healthier. Thus, a selection bias may exist in who received ASA and skew meaningful results.

For clinicians who care for joint arthroplasty patients postoperatively, this study adds to the growing literature supporting the use of aspirin as an acceptable option in preventing post-operative VTE. ${ }^{3-5}$ As acknowledged by the authors, an ongoing randomized, head-to-head comparison of aspirin vs. other agents will likely better answer this question

Corresponding Author: Gregory J. Misky, MD; University of Colorado Anschutz Medical Campus, Aurora, CO, USA (e-mail: Gregory. misky@ucdenver.edu).

\section{Compliance with Ethical Standards:}

Conflict of Interest: The author declares that he does not have a conflict of interest.

\section{REFERENCES}

1. Baumgartner C, Maselli J, Auerbach A, Fang M. Aspirin Compared to Anticoagulation to Prevent Venous Thromboembolism after Knee or Hip Arthroplasty: A Large Retrospective Cohort Study. J Gen Intern Med 5122

2. Falck-Ytter Y, Francis CW, Johanson NA, et al. Prevention of VTE in orthopedic surgery patients: Antithrombotic Therapy and Prevention of Thrombosis, 9th ed: American College of Chest Physicians Evidence-Based Clinical Practice Guidelines. Chest 2012;141:e278S-325S

3. Chu J, Maselli J, Auerbach A, Fang M. The risk of venous thromboembolism with aspirin compared to anticoagulants after hip and knee arthroplasty. Thromb Res 155: 65-72. 2017

4. Vincent V.G. et al. Aspirin as Thromboprophylaxis in Hip and Knee Arthroplasty: A Systematic Review and Meta-Analysis. J Arthroplast 31: 2608-2616. 2017

5. Anderson D.R. et al. Aspirin or Rivaroxaban for VTE Prophylaxis after Hip of Knee Arthroplasty. N Engl J Med 378:8. 2018

Publisher's Note: Springer Nature remains neutral with regard to jurisdictional claims in published maps and institutional affiliations. 